\title{
ĐIỀU TRI TỔN THƯƠNG PHỨC TẠP QUAI ĐỘNG MẠCH CHỦ BẦNG PHƯƠNG PHÁP HYBRID
}

\author{
Đoàn Đức Dũng*, Nguyễn Lân Hiếu*, Đỗ Anh Tiến**, Bùi Quang Thắng*, Trần Tiến Anh*, \\ Nguyễn Duy Thắng*, Bùi Đức Nhuận*, Bùi Văn Nhơn*
}

\section{TÓM TẮT}

Bệnh lý động mạch chủ rất đa dạng và có nguy cơ cao dẫn đến đột tử nếu bệnh nhân có triệu chứng. Bệnh lý động mạch chủ đoạn quai có các hình thái như phình, lóc tách, loét do xơ vữa, giả phình, hẹp eo động mạch chủ. Nguyên nhân của bệnh lý động mạch chủ hay gặp nhất là bệnh lý tăng huyết áp, ngoài ra có các nguyên nhân khác như nhiễm trùng, bệnh mô liên kết, chấn thương, bẩm sinh. Phẫu thuật điều trị bệnh lý động mạch chủ đoạn quai là phương pháp điều trị kinh điển nhưng có nguy cơi cao với những trường hợp bệnh lý tái phát hoặc ở bệnh nhân có bệnh lý nền nặng, thể trạng yếu, biến chứng chảy máu, nhiễm trùng xương ức, khó khăn cho gây mê hồi sức. Cách đây khoảng hơn 2 thập kỷ, phương pháp can thiệp đặt stent graft động mạch chủ ra đời, việc điều trị các bệnh lý động mạch chủ trở nên dễ dàng, triệt để và ít xâm lấn hơn, song song với tỷ lệ thành công cao hơn và giảm thiểu các biến chứng, do đó đây là một biện pháp điều trị thay thế phẫu thuật. Một tiêu chí quan trọng để tiến hành đặt stent graft là phần mạch lành từ gốc mạch máu quan trọng (động mạch cảnh, thân cánh tay đầu, động mạch tạng) đến điểm khởi phát tổn thương phải đủ dài để neo giữ stent và không bị rò ra ngoài lòng stent (landing zone). Kỹ thuật này đến nay đã trở nên phổ biến ở nhiều trung tâm can thiệp trong nước và trên thế giới với tỷ lệ thành công cao nếu tổn thương ở động mạch chủ xuống có landing zone tốt. Tuy nhiên với tổn thương ở vùng quai động mạch chủ, do vùng landing zone ngắn, là nơi xuất phát của nhiều mạch máu lớn nên việc thực hiện can thiệp đặt stent trở nên phức tạp hơn nhiều, đòi hỏi phải có sự phối hợp chặt chẽ giữa bác sỹ can thiệp và bác sỹ phẫu thuật, đây gọi là phương pháp
Hybrid. Phương pháp Hybrid bao gồm những kỹ thuật phức tạp nhất trong can thiệp bệnh lý động mạch chủ. Chúng tôi đã thực hiện phương pháp này trên 5 trường hợp bệnh nhân với kết quả khả quan, do đó chúng tôi muốn chia sẻ về kinh nghiệm và những hiểu biết của chúng tôi về kỹ thuật này.

\section{SUMMARY}

Aortic disease is diverse and carries a high risk of sudden death if the patient has symptoms. The aortic arch disease may be aneurysm, dissection, artherosclerotic ulcer, pseudoaneurysm, coracrtation. The most common cause is hypertension, others are infection, connective tissue disease, trauma, congenital. Surgical treatment is the clasic method, but it has high risks for the patients who were recurrent operation, severe comorbidity diseases. The operative risks compose of severe bleeding, sternal infection, complications relate to long time of anesthesia. More than two decades ago, when the aortic stent graft intervention was introduced, the treatment of aortic diseases became easier and less invasive. This method changed strategy of aortic disease treatment. The principle of this method is that through the artery (usually the femoral artery), an artificial vessel (stent graft) is implanted inside the lumen of the aorta, covering over the injury position. One of the most important thing for stent graft intervention is that the healthy vascular portion from the vital vascular ostium (carotid artery,

* Truò̀ng Đại học Y Hà Nội

** Bệnh viện $E$

Ngưòi chịu trách nhiệm khoa học: Đoàn Đức Dũng

Ngày nhận bài: 02/08/2020 - Ngày Cho Phép Đăng: 04/09/2020

Phản Biện Khoa học: PGS.TS. Đặng Ngoc Hùng PGS.TS. Đoàn Quốc Hung 
brachioencephalic artery, visceral artery) to the entrypoint of injury should be long enough to confirm the stent stably after implantation (the landing zone). This technique has become popular, easy to apply in many cathlabs in our country and in the world with a high success rate for Standford B type. However, with the injury in aortic arch, due to the short landing zone, which is the origin of many important blood vessels, the implantation of stent graft becomes much more complicated, requiring close coordination between the interventionist and the surgeon, this is called the hybrid method. Hybrid method includes the most complex techniques in aortic intervention. We used this method on series of 5 cases with feasible results, so we want to share our experience and knowledge about this technique.

\section{TỔNG QUAN}

\subsection{Phân loại tổn thương động mạch chủ đoạn quai.}

1.1.1. Theo hình thái tổn thương: Lóc tách động mạch chủ, phình động mạch chủ, giả phình động mạch chủ.

\subsubsection{Theo vị trí của tổn thưong:}

- Standford phân loại thành: Type A (tổn thương đoạn động mạch chủ lên cho dù khởi phát ở bất kỳ đoạn động mạch chủ nào), Type $\mathrm{B}$ (thương tổn động mạch chủ đoạn xa kể từ chỗ xuất phát của động mạch dưới đòn trái). Do đó tổn thương phần quai động mạch chủ thuộc type $\mathrm{A}$.

- DeBakey phân loại thành: Type I (tổn thương cả động mạch chủ lên và động mạch chủ xuống), Type II (tổn thương chỉ ở động mạch chủ lên), Type III (tổn thương chỉ ở đoạn động mạch chủ dưới). Theo phân loại này, tổn thương phần quai thuộc type II.

\subsubsection{Theo thò̀i gian bị bệnh:}

Đối với tổn thương lóc tách động mạch chủ, theo thời gian khởi phát bệnh phân loại thành:

- Lóc tách cấp tính: Thời gian kể từ khi khởi phát dưới 2 tuần.
- Lóc tách mạn tính: Thời gian kể từ khi khởi phát trên 2 tuần.

\subsection{Phương pháp phẫu thuật điều trị} bệnh lý động mạch chủ đoạn quai.

1.2.1. Phuơng pháp phẫu thuật đự̛c chỉ định đối với tổn thương phần quai động mạch chủ:

- Lóc tách cấp tính có biến chứng hoặc chưa có biến chứng.

- Phình động mạch chủ đoạn gần có triệu chứng hoặc kích thước tiến triển nhanh trên $1 \mathrm{~cm} /$ năm, hoặc đường kính động mạch chủ trên $55 \mathrm{~mm}$.

\subsubsection{Kỹ thuật phẫu thuật phần quai: Mục} đích của phẫu thuật nhằm cắt bỏ và thay thế đoạn động mạch chủ bị tổn thuơng đối với phinh hoặc giả phình động mạch chủ, cắt bỏ và thay thế đoạn động mạch có vết rách đầu tiên phối hơp với dán keo đối với lóc tách động mạch chủ

- Tổn thương động mạch chủ phần quai lan tới động mạch chủ lên không gây hở chủ: Phẫu thuật thay động mạch chủ lên.

- Tổn thương động mạch chủ phần quai và/hoặc động mạch chủ lên kèm hở chủ: Phẫu thuật Bentall nếu không thể sửa được van động mạch chủ (thay đoạn gốc động mạch chủ, cắm lại động mạch vành).

- Tỷ lệ tử vong quanh phẫu thuật động mạch chủ nếu tổn thương chưa có biến chứng giao động từ $5-10 \%$. Đối với tổn thương động mạch chủ đã có biến chứng, tỷ lệ tử vong xung quanh phẫu thuật có thể lên tới $70-80 \%$. Các biến chứng sớm của phẫu thuật gồm chảy máu, nhiễm trùng, hoại tử ống thận cấp, thiếu máu mạc treo, liệt 2 chi dưới do thiếu máu tuỷ sống. Biến chứng muộn gồm hở chủ tiến triển, tổn thương phình/lóc tái phát, tồn lưu tổn thương sau mổ.

\subsection{Can thiệp đặt stent graft động mạch chủ phần quai: \\ Năm 1991, tác giả Nikolay Volodo và cộng sự đã công bố ca can thiệp phần quai động mạch chủ đầu tiên trên thế giới bằng phương}


pháp Hybrid thành công. Chỉ định có ý nghĩa hợp nặng, thể trạng yếu. Trong can thiệp đặt nhất là đối với những bệnh nhân thuộc nhóm stent graft động mạch chủ ngực, cung động nguy cơ cao của phẫu thuật như bệnh nhân đã mạch chủ được chia thành 4 vùng từ Zone 0 đến được phẫu thuật mở ngực trước đó, bệnh lý phối Zone 4.

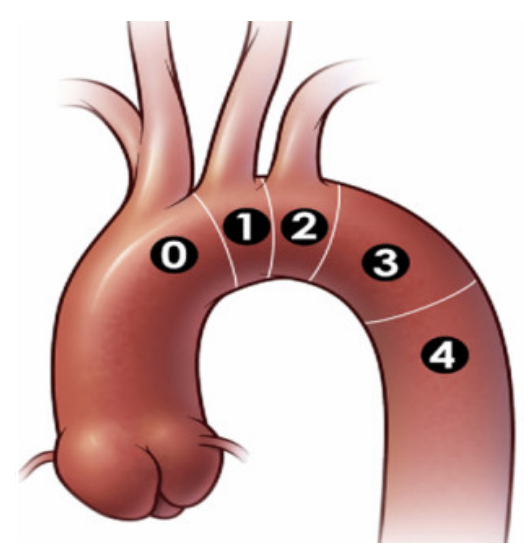

Hình 1: Phân chia động mạch chủ thành 4 vùng từ zone 0 đến zone 4 [nguồn Internet].

Zone 0: Stent được đặt ở động mạch chủ lên đến ngay sau gốc thân cánh tay đầu. Zone 1: Stent được đặt ở vị trí của gốc động mạch cảnh chung trái. Zone 2: Stent được đặt ở vị trí của gốc động mạch dưới đòn trái. Zone 3: Stent được đặt ở vị trí eo động mạch chủ. Zone 4: Stent được đặt ở động mạch chủ xuống.

Cách phân chia này có ý nghĩa định hướng cho việc bắc cầu các nhánh mạch xuất phát từ vùng quai.

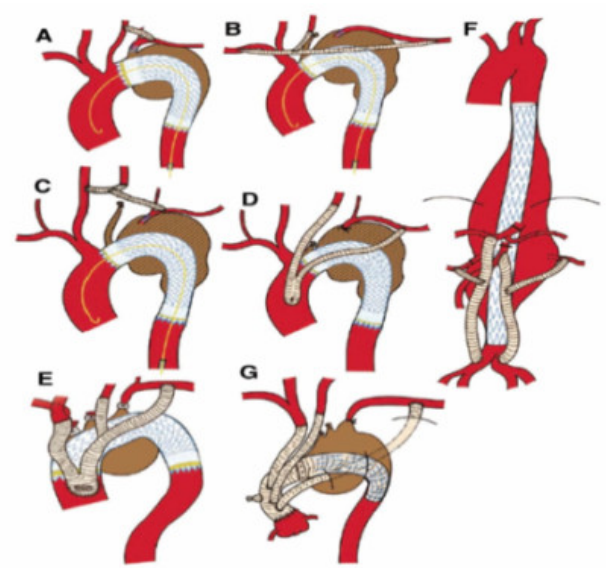

Hình 2: Các phương pháp bắc cầu phụ thuộc vào vị trí của stent vào vùng zone 0 đến zone 4 [nguồn Internet].

Hình F: bắc cầu cho zone 4; hình A,B: bắc cầu cho zone 2,3; Hình C,D: bắc cầu cho zone 1; Hìn E, G: bắc cầu cho zone 0

1.3.1. Can thiệp đặt stent graft sát gốc thân cánh tay đầu (zone 1).

Kỹ thuật này áp dụng khi vùng mạch lành tính từ ngay sau gốc thân cánh tay đầu đến vị trí xuất phát của tổn thương (landing zone) đủ dài, thông thường trên $2 \mathrm{~cm}$. Khi thực hiện thủ thuật này, stent sẽ phủ qua gốc của động mạch dưới đòn và cảnh chung trái do đó phải chuyển vị tưới máu các mạch này trước can thiệp.

Bác sỹ phẫu thuật: Tiến hành phẫu thuật bắc cầu các mạch máu vùng quai không mở ngực (động mạch cảnh phải - động mạch cảnh 
trái hoặc động mạch cảnh phải - cảnh trái dưới đòn trái).

Bác sỹ can thiệp: Tiến hành đặt stent graft phủ kín tổn thương phục hồi cấu trúc giải phẫu lòng mạch và đảm bảo dòng máu chảy thông qua cầu nối.

\subsubsection{Can thiệp đặt stent graft động mạch} chủ lên có mở ngục (zone 0).

Bác sỹ phẫu thuật: Qua đường mở ngực cưa xương ức, bác sỹ phẫu thuật làm cầu nối từ động mạch chủ lên - thân cánh tay đầu, động mạch cảnh chung trái, động mạch dưới đòn trái nếu stent đặt qua gốc thân cánh tay đầu. Miệng cầu nối phía động mạch chủ ở vị trí đủ thấp để vùng landing zone dài nhất có thể.

Bác sỹ can thiệp: Đặt stent graft đến động mạch chủ lên, phía trên miệng nối của cầu động mạch. Stent sẽ đặt qua gốc nguyên uỷ của cả mạch xuất phát ở quai.

\subsubsection{Can thiệp đặt stent graft đến động} mạch chủ lên không mở ngục có sử dụng kỹ thuật đặt stent nhánh bên (chimney technique): Kỹ thuật này áp dụng khi landing zone ngắn dưới 2 cm, nguy cơ rò cao, bệnh nhân đã được phẫu thuật lồng ngực có cưa xương ức trước đó hoặc nguy cơ phẫu thuật cao. Một tiêu chí quan trọng khác là phần động mạch chủ lên (zone 0 ) có kích thước bình thường và lành. Do đó bác sỹ phải tiến hành đặt stent đồng thời động mạch chủ lên và stent thân cánh tay đầu. Nguy cơ gập stent nhánh, nguy cơ rò, nguy cơ tai biến cao nên đây là kỹ thuật phức tạp nhất trong can thiệp đặt stent graft động mạch chủ.

Bác sỹ phẫu thuật: Làm cầu nối động mạch cảnh phải - động mạch cảnh trái có thể kèm theo cầu động mạch cảnh trái - dưới đòn trái.
Bác sỹ can thiệp: Đặt stent động mạch chủ lên và đồng thời đặt stent thân cánh tay đầu.

\section{II. ĐỐI TƯợNG VÀ PHƯƠNG PHÁP NGHIÊN CÚ'U}

\section{1. Đối tượng nghiên cứu:}

Bao gồm 5 trường hợp lâm sàng tổn thương phần quai động mạch chủ được thực hiện phương pháp Hybrid tại bệnh viện Đại học Y Hà nội từ năm 2016 - 2018 .

\subsection{Phương pháp nghiên cứu:}

Thiết kế nghiên cứu: Mô tả hàng loạt ca bệnh.

\subsection{Các bước tiến hành:}

- Kế hoạch thực hiện điều trị được hội chẩn và bàn bạc kỹ lưỡng: Các bước và các thì thực hiện, lựa chọn dụng cụ dựa trên phân tích hình ảnh của phim chụp cắt lớp vi tính đa dãy lớp mỏng.

- Phương pháp vô cảm: Gây mê nội khí quản.

- Nơi thực hiện: Phòng mổ - Phòng can thiệp hoặc phòng Hybrid.

- Thì đầu tiên: Bác sỹ phẫu thuật làm cầu nối động mạch cảnh phải - cảnh trái hoặc động mạch cảnh phải - động mạch cảnh trái - động mạch dưới đòn trái.

- Thiết lập đường vào: Động mạch đùi chung bên phải, động mạch đùi chung bên trái, động mạch dưới đòn phải hoặc động mạch cánh tay phải.

- Heparin đường tĩnh mạch: Đảm bảo APTT đạt 1,5-2 so với nhóm chứng.

- Chụp động mạch chủ: Sử dụng kỹ thuật chụp xoá nền có máy bơm thuốc cản quang để đánh dấu tổn thương.

Chụp cầu nối: chụp kiểm tra cầu nối để đảm bảo cầu nối thông và tưới máu não bình thường sau mổ bắc cầu 


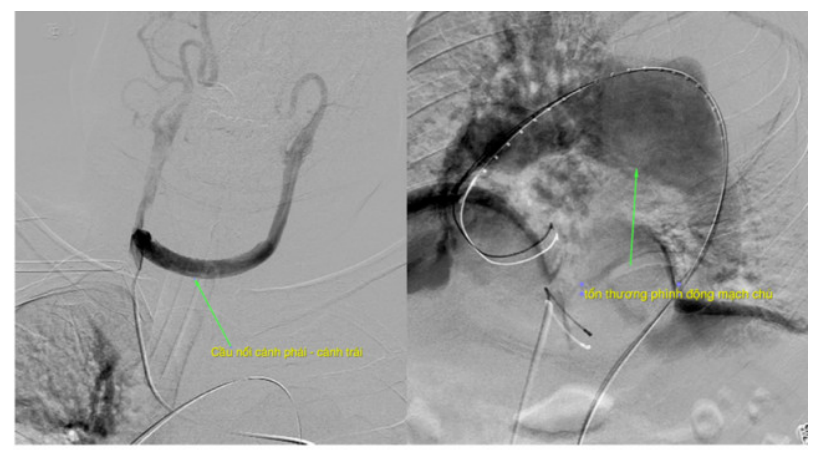

Hình 3: Chụp kiểm tra cầu nối và tổn thương quai động mạch chủ

- Đặt stent graft đến sát ngay sau thân động mạch cánh tay đầu: Sử dụng ống thông Pigtail để đánh dấu gốc thân cánh tay đầu, sau đó đặt stent ngay sát mép sau của gốc động mạch này.

- Đặt stent graft đến động mạch chủ lên có mở ngực: Sử dụng ống thông pigtail đi từ động mạch quay hoặc cánh tay bên phải đưa đến miệng cầu nối ở động mạch chủ lên. Stent được đặt ngay phía trên của miệng nối đã được đánh dấu.
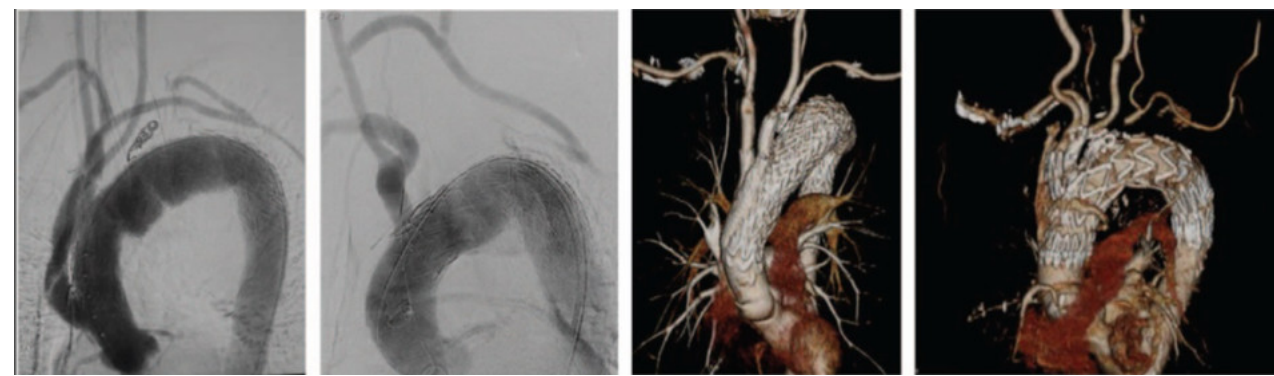

Hình 4: Đặt stent graft động mạch chủ lên có mở ngực

Đối với kỹ thuật đặt stent graft có mở ngực làm cầu nối, tuỳ thuộc vào sự lan rộng của tổn thương mà có các type làm cầu nối khác nhau.
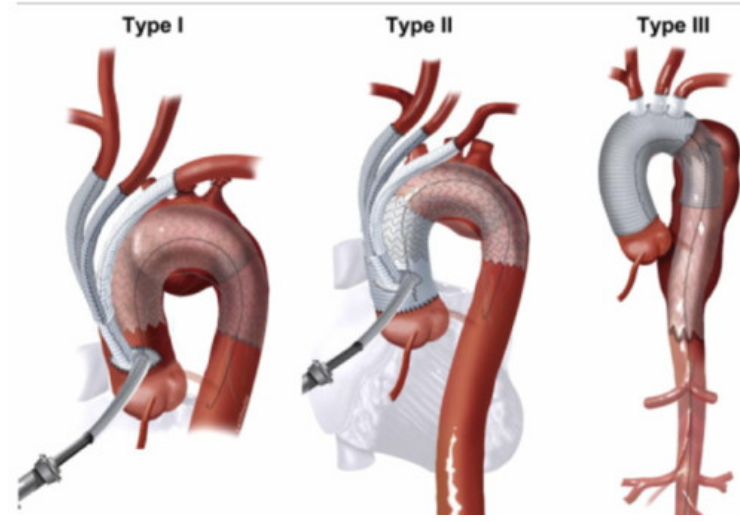

Hình 5: Các type làm cầu nối trong can thiệp đặt stent graft phần quai

Type 1: áp dụng với tổn thương khu trú vùng quai và không lan đến động mạch chủ lên; Type 2: áp dụng với tổn thưong lan đến động mạch chủ lên; Type 3: áp dụng với tổn thương lan đến cả động mạch chủ lên và động mạch chủ xuống

- Đặt stent graft đến gốc động mạch chủ không mở ngực có đặt stent thân cánh tay đầu: Stent được đặt phía trên chỗ xuất phát của 2 động mạch vành khoảng $3 \mathrm{~cm}$ và đặt đồng thời stent graft 
nhánh động mạch cánh tay đầu (chimney technique). Đầu tiên stent động mạch chủ được mở khoảng 2-3 mắt, sau đó stent nhánh bên được mở phần đầu. Tiếp đó 2 stent được thả đồng thời để dòng máu làm nở đều 2 stent cho đến hết stent. Dây dẫn đường cho stent có thể được đặt vào trong thất trái hoặc đặt ở gốc động mạch chủ. Nếu dây dẫn đặt trong buồng thất trái, cần phải đặt máy tạo nhịp tạm thời đề phòng biến chứng rối loạn nhịp trong thủ thuật.

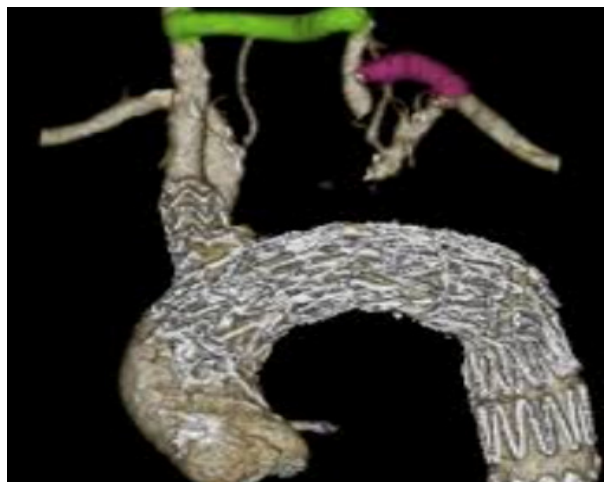

Hình 6: Đặt stent động mạch chủ lên không mở ngực

- Chụp kiểm tra: chụp động mạch chủ, chụp stent thân cánh tay đầu và cầu nối 2 động mạch cảnh, động mạch dưới đòn.

- Đóng đường vào: Đường vào được đóng bằng phẫu thuật hoặc dụng cụ đóng mạch.

\section{KẾT QUẢ VÀ BÀN LUẬN}

\subsection{Kết quả}

\subsection{1. Đặc điểm lâm sàng}

Chúng tôi tiến hành phương pháp Hybrid cho 5 bệnh nhân tuổi từ 34 đến 75 tuổi, nam/nữ = 4/1, bao gồm:

- 2 bệnh nhân phình động mạch chủ đoạn quai có triệu chứng đau ngực và khàn tiếng, có bệnh mạch vành nặng phối hợp.

- 1 bệnh nhân phình động mạch chủ đoạn quai có biến chứng vỡ vào khoang màng phổi trái.

- 1 bệnh nhân lóc tách động mạch chủ tồn dư phần quai sau phẫu thuật thay động mạch chủ lên (trước phẫu thuật là lóc tách Standford $\mathrm{A}$ ).

- 1 bệnh nhân có lóc tách tái phát phần quai sau can thiệp đặt stent động mạch chủ xuống và phẫu thuật thay động mạch chủ lên (trước phẫu thuật là lóc tách Standford A).

Tất cả bệnh nhân đều có bệnh nền là tăng huyết áp, 1 bệnh nhân có tiền sử thay đoạn động mạch chủ lên cách 2 tháng, 1 bệnh nhân có tiền sử thay đoạn động mạch chủ lên và đặt stent graft trước đó 3 năm, 2 bệnh nhân có bệnh lý mạch vành kèm theo. Có 1 bệnh nhân được thực hiện thủ thuật cấp cứu, 4 bệnh nhân được thực hiện có chuẩn bị.

3.1.2. Tỷ lệ thành công: Tỷ lệ thành công về mặt kỹ thuật đạt $5 / 5$.

3.1.3. Biến chứng: Có 3 bệnh nhân có biến chứng đáng kể trong và sau thủ thuật:

- Biến chứng rối loạn nhịp: Một bệnh nhân bị loạn nhịp chậm và vô tâm thu trong thủ thuật.

- Biến chứng thủng xoang valsava không vành vào thất phải.

- Biến chứng thiếu máu và nhồi máu não trong quá trình hồi sức sau can thiệp.

- Không có bệnh nhân nào tử vong.

\subsection{Bàn luận}

3.2.1. Đặc điểm lâm sàng: Tất cả bệnh nhân trong nghiên cứu của chúng tôi đều là bệnh nhân có nguy cơ cao đối với phẫu thuật do tình trạng bệnh lý nền nặng, thể trạng yếu, mổ cưa xương ức cũ. Các nghiên cứu đã được công bố trên thế giới cũng nhấn mạnh đặc điểm tương tự ở bệnh nhân được điều trị bằng phương pháp 
Hybrid. Tác giả Nadia Vallejo đã công bố một nghiên cứu hồi cứu với 38 bệnh nhân, trong đó có tỷ lệ 12/38 bệnh nhân lóc tách type $A, 10 / 38$ bệnh nhân phình quai động mạch chủ, $8 / 38$ bệnh nhân lóc tách Standford B, $3 / 38$ bệnh nhân phình động mạch chủ xuống, còn lại là rò động mạch chủ vào phế quản, phình thân cánh tay đầu, giả phình quai động mạch chủ. Trong nghiên cứu của chúng tôi có tỷ lệ $2 / 5$ bệnh nhân lóc tách động mạch chủ Standford $A$, còn lại 3/5 bệnh nhân phình động mạch chủ đoạn quai với độ tuổi từ 34 đến 75 tuổi, tỷ lệ nam/nữ là $4 / 1$. Bệnh lý nền trong nhóm bệnh nhân của chúng tôi bao gồm tiền sử bệnh giang mai, tăng huyết áp, bệnh lý mạch vành, đái tháo đường. Nghiên cứu của nhiều tác giả khác cũng ghi nhận tiền sử tăng huyết áp gặp ở hầu hết những bệnh nhân có tổn thương phình hoặc lóc động mạch chủ. Những bệnh nhân lóc tách Standford A ở các nghiên cứu trên thế giới thường được can thiệp thì đầu và ngay sau phẫu thuật động mạch chủ lên. Trong nghiên cứu của chúng tôi, 1 bệnh nhân lóc tách type A được can thiệp thì 2 sau phẫu thuật 2 tháng. Một bệnh nhân được phẫu thuật thay động mạch chủ lên và đặt stent graft động mạch chủ xuống trước đó 3 năm. Chỉ định can thiệp thì 2 với 2 bệnh nhân này là do bệnh nhân có biểu hiện thiếu máu tạng và lóc tách tái phát sau phẫu thuật, can thiệp. Hai bệnh nhân phình quai động mạch chủ có biểu hiện đau ngực và khàn tiếng, đây là biểu hiện lâm sàng điển hình của phình quai động mạch chủ đã được mô tả trong y văn. Biểu hiện đau ngực sau xương ức, đau liên tục và âm ỉ có thể đau xuyên ra sau lưng là biểu hiện của nguy cơ vỡ phình động mạch chủ. Kích thước lớn nhất của khối phình trong nghiên cứu của chúng tôi là $105 \mathrm{~mm}$. Trong nghiên cứu của Yoshihiko Kurimoto, có 33 bệnh nhân phình quai động mạch chủ được can thiệp đặt stent graft, kích thước lớn nhất của túi phình lên tới 303 mm.

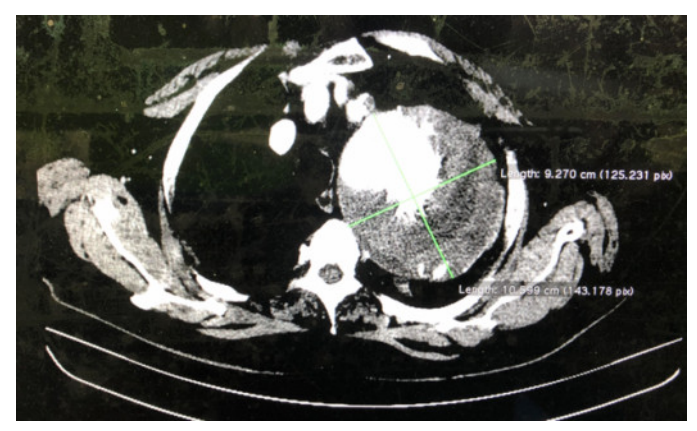

Hình 7: Túi phình lớn vùng quai động mạch chủ trong nghiên cứu

Biến chứng vỡ phình động mạch chủ thường đến sau biểu hiện lâm sàng này, thường liên quan đến trạng thái gắng sức, ho, chấn thương va đập, cơn tăng huyết áp và những hoạt động gia tăng áp lực lồng ngực. Một bệnh nhân đến với chúng tôi trong bệnh cảnh cấp cứu do vỡ khối phình vào màng phổi trái.
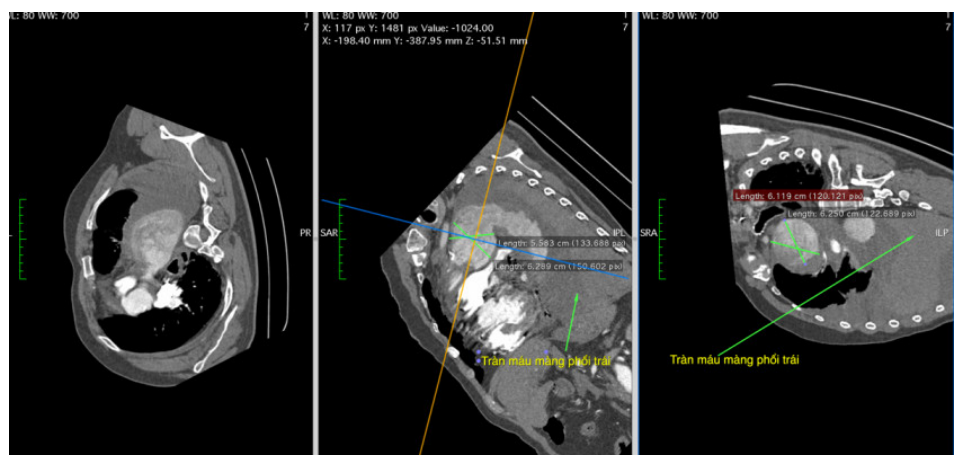

Hình 8: Phình động mạch chủ biến chứng vỡ vào khoang màng phổi trái 
Trong nghiên cứu của Nadia Vallejo, tỷ lệ bệnh nhân nhập viện trong bệnh cảnh cấp cứu chiểm $26 \%$.

3.2.2. Đặc điểm kỹ thuật: Trong nghiên cứu của chúng tôi, cả 5 bệnh nhân đều được thực hiện phương pháp Hybrid không mở ngực. Có 2 bệnh nhân được đặt Stent đến zone 1 động mạch chủ. Có 3 bệnh nhân được đặt đến zone 0 động mạch chủ và đặt stent nhánh thân cánh tay đầu.

Với kỹ thuật đặt stent đến zone 1 , cầu nối động mạch cảnh phải - động mạch cảnh trái kèm hoặc không kèm động mạch dưới đòn trái được thực hiện trong thì đầu. Ở thì 2 , stent graft được đặt ở ngay sau gốc của thân cánh tay đầu. Một số trường hợp nếu gốc của thân cánh tay đầu không bị hẹp, đầu gần của stent có thể được đặt tiến vào một phần của gốc động mạch này để tăng khả năng cố định của stent, thường áp dụng cho những bệnh nhân có phình quai lớn, có nguy cơ di lệch và trôi stent vào khối phình sau khi đặt.

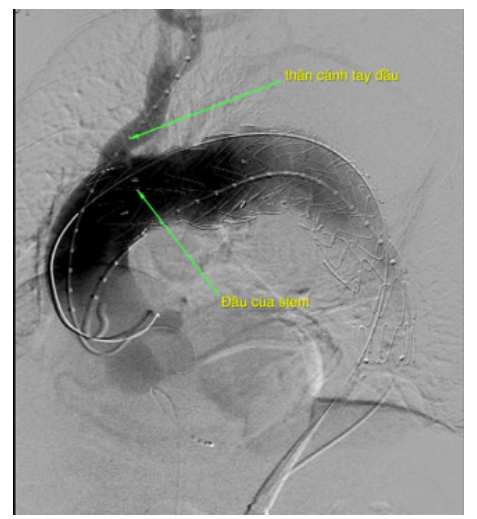

Hình 9: Stent graft được đặt ở vùng zone 1

Nghiên cứu của Nadia Vallejo, tỷ lệ đặt stent vùng zone 1 đối với bệnh nhân bệnh lý vùng quai động mạch chủ là 11/38. Kỹ thuật này dễ áp dụng và được chỉ định đối với những bệnh nhân có khối phình quai không lớn hoặc lóc tách động mạch chủ type $B$ lan ngược lên quai động mạch chủ hoặc có vùng landing zone ngắn. Trong quá trình thực hiện thủ thuật, thông thường chúng tôi sử dụng 2 đường vào: Một đường động mạch đùi chung (thường ở bên phải), một đường động mạch quay phải. Đường động mạch đùi chung được thiết lập bởi mở mạch bằng phẫu thuật hoặc perclose, được sử dụng để đẩy và thả dụng cụ. Đường động mạch quay để đưa vào thân cánh tay đầu xuống động mạch chủ lên với mục đích đánh dấu động mạch chủ lên và kết nối máy chụp thuốc cản quang. Đầu tiên chúng tôi sử dụng ống thông Pigtail với sự dẫn đường của dây dẫn Terumo đầu cong 0,035 inch, đi vào đường động mạch đùi lên động mạch chủ lên. Sau đó chúng tôi rút dây dẫn Terumo và thay bằng dây dẫn siêu cứng. Qua đường ống thông Pigtail của động mạch quay, phim chụp cung động mạch chủ được thực hiện để đánh dấu tổn thương và vị trí giải phẫu của các nhánh mạch vùng quai. Stent graft đã được lựa chọn về kích thước và chiều dài dựa trên tính toán của phim chụp MSCT, được đưa vào động mạch chủ lên qua đường động mạch đùi và dây dẫn siêu cứng dẫn đường. Khi stent đúng vị trí, chúng tôi thực hiện thao tác thả stent ở góc nghiêng trái 45-60 độ. Trong quá trình thả stent, việc chụp kiểm tra vị trí của stent được thực hiện lặp lại để đảm bảo stent đúng vị trí và không di lệch. Nếu quá trình thả những mắt stent đầu tiên, khi đầu stent bị di lệch, chúng tôi có thể dễ dàng điều chỉnh, tuy nhiên khi stent đã được thả trên $1 / 3$ chiều dài, việc điều chỉnh là khó khăn do áp lực của lòng động mạch chủ đầy stent áp sát vào thành. 


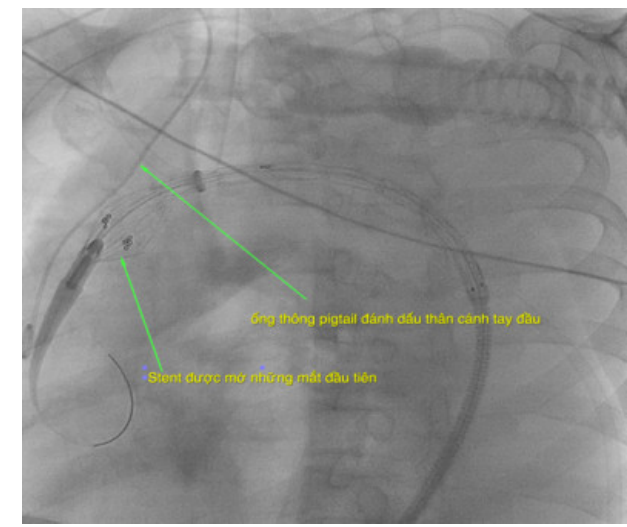

Hình 10: Mở stent và thân cánh tay đầu được đánh dấu bởi ống thông Pigtail

Kỹ thuật đặt stent graft ở vùng zone 0 được thực hiện ở 3 bệnh nhân còn lại. So với kỹ thuật đặt ở các vùng còn lại, đây là kỹ thuật khó nhất và phức tạp nhất. Về mặt kỹ thuật có sự khác biệt đối với đặt stent vùng zone 1 . Đường vào là động mạch đùi 2 bên, một bên để đưa stent lên, một bên để đưa ống thông Pigtail lên gốc có kết nối bơm chụp cản quang. Một đường nữa là động mạch cánh tay hoặc động mạch dưới đòn bên phải, đường này dùng để đặt stent thân cánh tay đầu.
Hai dây dẫn siêu cứng được đưa vào động mạch đùi và động mạch cánh tay (hoặc dưới đòn bên phải) vào thân cánh tay đầu. Đầu dây dẫn đường cho stent động mạch chủ có thể được đưa vào trong buồng thất trái, đầu dân dẫn còn lại đặt ở gốc động mạch chủ. Để phòng biến chứng rối loạn nhịp trong lúc thực hiện thủ thuật, cần đặt máy tạo nhịp tạm thời để chế độ chờ. Có một số tác giả để cả 2 đầu dây dẫn ở gốc động mạch chủ.

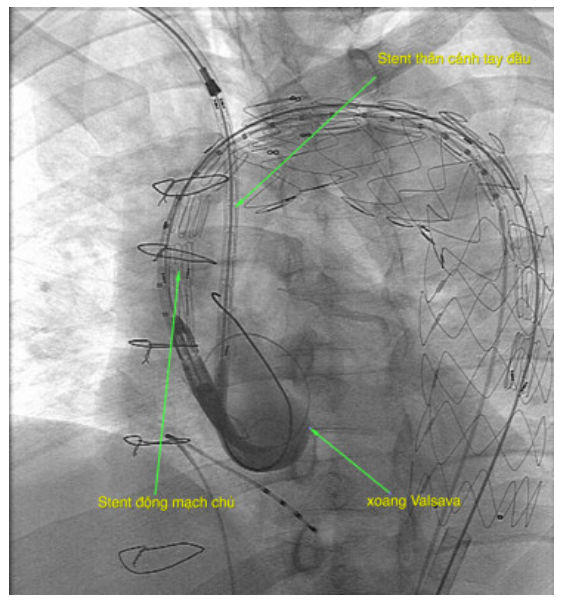

Hình 11: Vị trí của stent động mạch chủ và stent thân cánh tay đầu trước thả

Trong thao thác thả stent sẽ có 1 người thả stent động mạch chủ, 1 người thả stent nhánh thân cánh tay đầu, các bác sỹ còn lại sẽ phối hợp để giữ cho dây dẫn ổn định. Trước tiên, stent động mạch chủ sẽ được thả chậm cho đến khoảng 3 mắt đầu tiên, sau đó stent thân cánh tay đầu cũng được mở những mắt phần đầu, đầu xa của stent cánh tay đầu phải thấp hơn đầu xa của stent động mạch chủ khoảng $1 \mathrm{~cm}$. Để đảm bảo mối tương quan của 2 stent và khoảng cách an toàn với động mạch vành, việc thực hiện phim chụp động mạch chủ là bắt buộc, thông thường tư thế nghiêng bóng 45-60 độ. 


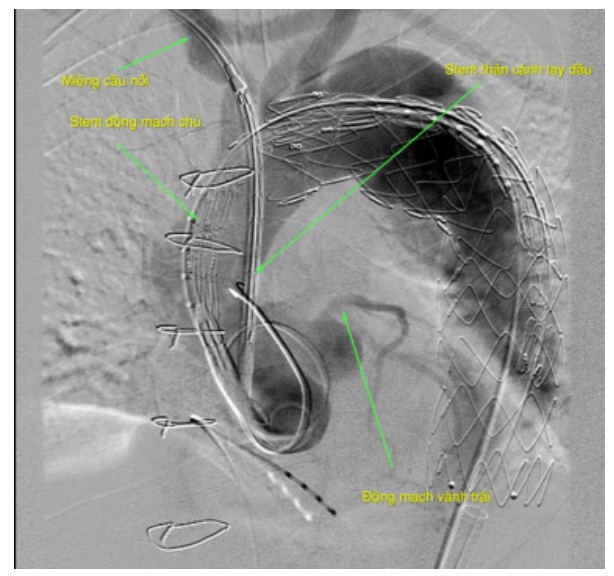

Hình 12: Chụp kiểm tra 2 stent và khoảng cách tới động mạch vành

Khi vị trí của 2 stent ổn định và khoảng cách tới động mạch vành phù hợp, cả 2 stent sẽ được thả đồng thời và nhịp nhàng để 2 stent khi nở ra sẽ áp sát nhau. Đối với stent thân cánh tay đầu cần chú ý đầu xa của stent phải được căn chỉnh khi thả sao cho ở phía trước ngã 3 chia đôi động mạch cảnh chung và động mạch dưới đòn. Vị trí ngã 3 này phải được đánh dấu bằng phim roadmap (phim nhớ hình giải phẫu mạch máu bằng thuốc cản quang). Trong khi thực hiện thao tác thả có thể để máy tạo nhịp ở tần số nhanh phù hợp để giảm huyết áp, giảm thiểu nguy cơ di lệch stent. Stent đặt cho thân cánh tay đầu có kích thước bằng với kích thước thân cánh tay đầu, đồng thời phải có độ cứng của chất liệu tương đương với stent động mạch chủ. Nếu độ cứng của stent thân cánh tay đầu khác biệt với nhánh động mạch chủ, sẽ có nguy cơ gập stent nhánh hoặc rò giữa 2 stent.

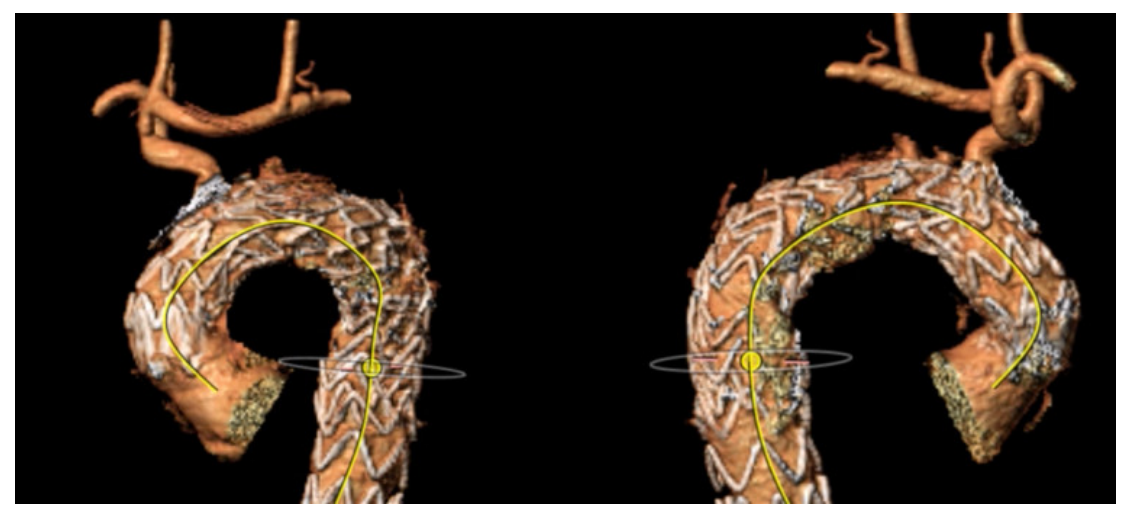

Hình 13: Hình ảnh MSCT sau can thiệp của bệnh nhân được áp dụng kỹ thuật Chimney technique.

Trong nghiên cứu của Nadia Vallejo, trong số 27 bệnh nhân được đặt stent vùng zone 0 , chỉ có 5 bệnh nhân được thực hiện kỹ thuật Chimney technique, những bệnh nhân này có tiền sử mở ngực cưa xương ức trước đó và có nguy cơ của phẫu thuật cao.
Với tổn thương phần quai động mạch chủ phải đặt stent đến vùng zone 0 , tác giả Yoshihiko Kurimoto có cách tiếp cận khác khi ông không sử dụng sỹ thuật Chimney hay bắc cầu ở một số trường hợp. Trong nghiên cứu của ông với 37 trường hợp bệnh nhân phình động mạch chủ phải 
can thiệp đến vùng zone 0 , có có áp dụng một vài trường hợp sử dụng Stent graft mở cửa sổ. Kỹ thuật này sử dụng loại stent được mở cửa sổ với kích thước khoảng cách phù hợp với cách nhánh của quai động mạch chủ, dựa trên sự đo đạc chính xác của phim MSCT. Kỹ thuật này có ưu điểm là không phải phẫu thuật bắc cầu cũng như bảo tồn được vị trí nguyên uỷ nơi xuất phát của mạch máu vùng quai. Nhược điểm là mất thời gian để thiết kế và sản xuất không phù hợp cho bệnh nhân cấp cứu, ngoài ra có nguy cơ rò qua vị trí cửa sổ vào túi phình.

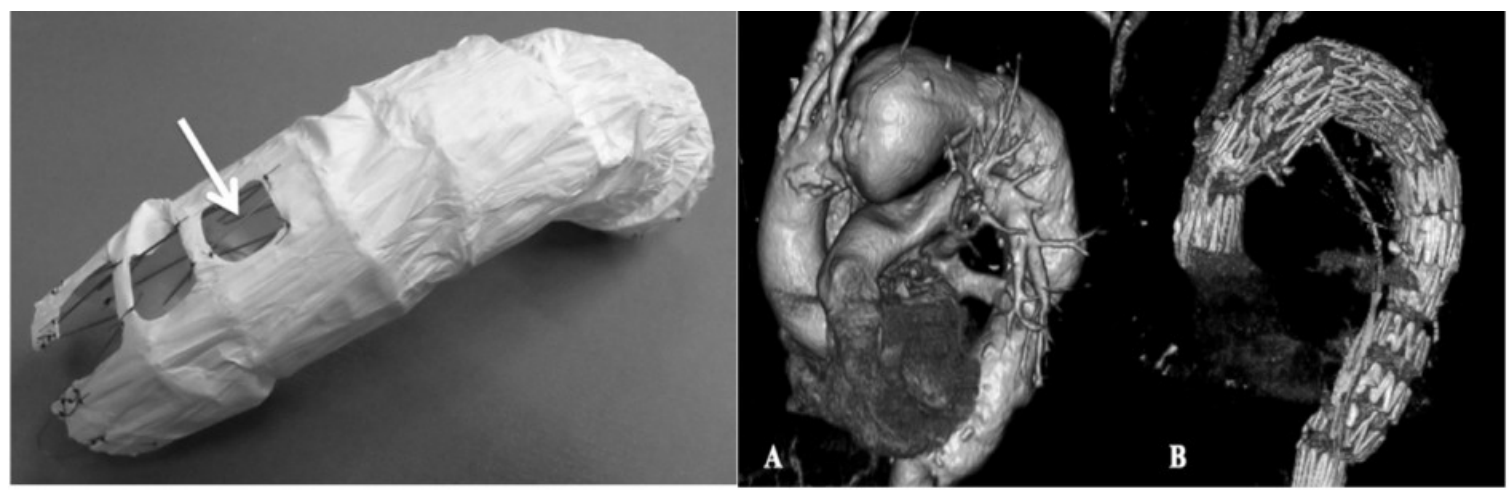

Hình 14: Một trường hợp phình động mạch chủ được can thiệp tới vùng zone 0 sử dụng stent graft mở cửa sổ

\subsubsection{Tỷ lệ thành công và biến chứng}

Tỷ lệ thành công về mặt kỹ thuật trong can thiệp Hybrid điều trị bệnh lý quai động mạch chủ lên tới 95\% đến 100\% qua các nghiên cứu. Trong nghiên cứu của chúng tôi, tỷ lệ thành công về mặt kỹ thuật đạt $100 \%$.

Tỷ lệ tử vong sớm trong vòng 1 tháng sau thủ thuật từ $0-29,6 \%$, nguyên nhân tử vong được kể đến là liệt tuỷ, đột quy, nhồi máu cơ tim, suy hô hấp, suy đa tạng, chảy máu trong. Nghiên cứu của chúng tôi không ghi nhận trường hợp tử vong nào. Tỷ lệ sống sau 1 năm đạt $5 / 5$.

Biến chứng được ghi nhận trong can thiệp động mạch chủ vùng zone 0 gồm đột quy, liệt ngoại biên, nhồi máu cơ tim, suy thận, chảy máu, suy hô hấp, nhiễm trùng, rối loạn nhịp. Tỷ lệ biến chứng gộp có thể lên tới trên $30 \%$. Trong nghiên cứu của chúng tôi cũng ghi nhận 3 loại biến chứng: Biến chứng rối loạn nhịp, biến chứng thủng xoang valsava không vành vào thất phải, biến chứng nhồi máu não.

\section{Biến chứng rối loạn nhịp xảy ra ở 2 bệnh nhân:}

Bệnh nhân đầu tiên xảy ra rối loạn nhịp vô tâm thu khi đưa dụng cụ đến động mạch chủ lên với dây dẫn nằm trong buồng thất trái. Chúng tôi xử trí bằng cách rút lại hệ thống dây dẫn và dụng cụ về động mạch chủ xuống, bật máy tạo nhịp. Sau khoảng 1 phút, nhịp của bệnh nhân phục hồi về nhịp xoang. Chúng tôi cho rằng nguyên nhân có thể do dụng cụ khi đưa vào động mạch chủ lên, phần đầu hệ thống thả đi vào phần đường ra thất trái chèn ép đường dẫn truyền. Khi tình trạng huyết động và nhịp tim về bình thường, chúng tôi tiến hành đặt dây dẫn ở gốc động mạch chủ.

Bệnh nhân thứ 2 có biểu hiện rung nhĩ nhanh sau thủ thuật kèm theo chảy máu màng phổi bên trái tiếp tục gây tụt áp. Bệnh nhân được xử trí bù khối lượng tuần hoàn, truyền máu, dùng thuốc rối loạn nhịp phục hồi nhịp xoang. 


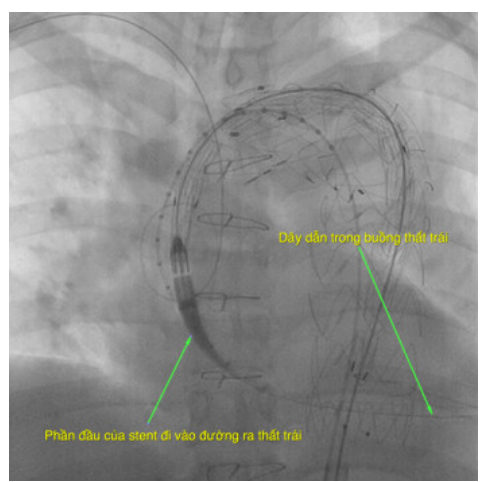

Hình 15: Biến chứng vô tâm thu khi phần đầu dụng cụ đi đường ra thất trái với dây dẫn trong buồng thất trái.

Biến chứng thủng xoang valsava không vành vào thất trái: Biến chứng này xảy ra ở một bệnh nhân. Sau khi thả xong stent động mạch chủ và thân cánh tay đầu, chúng tôi chụp kiểm tra phát hiện ra biến chứng này. Để xử trí biến chứng này, chúng tôi tiến hành lái dây dẫn Terumo 0,035 inch qua lỗ thủng vào thất phải lên tĩnh mạch chủ trên. Từ đường tĩnh mạch đùi chúng tôi bắt thòng lọng kéo dây dây ra ngoài. Sau đó chúng tôi tiến hành bít xuôi dòng lỗ thủng bằng dụng cụ ADO1 kích thước $12 \times 10 \mathrm{~mm}$ che kín hoàn toàn tổn thương.

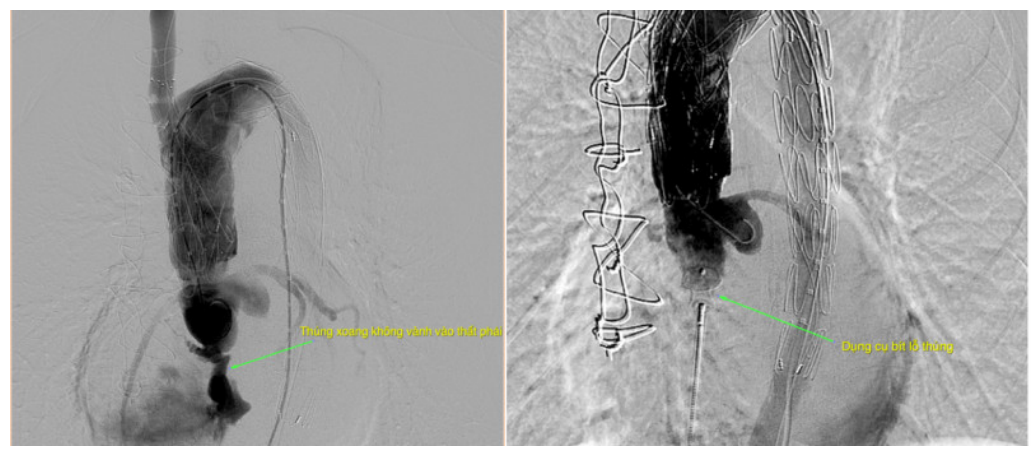

Hình 16: Biến chứng thủng xoang không vành và dụng cụ kín bít lỗ thủng

Chúng tôi tìm hiểu nguyên nhân của biến chứng này và thấy rằng trong quá trình thả dụng cụ, đầu dây dẫn của stent động mạch chủ đã bị trôi ra đến phần mềm của dây và không đủ bảo vệ, do đó phần đầu nhọn của hệ thống thả đã đâm thủng xoang không vành. Để tránh biến chứng này đòi hỏi người phụ phải phối hợp rất nhịp nhàng trong quá trình thao tác đảm bảo cho dân dẫn đủ độ dài cần thiết.

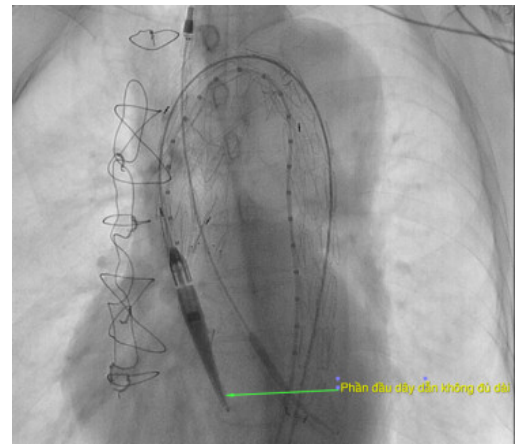

Hình 17: Phần dây dẫn bị trôi ra đến phần mềm của dây 
Biến chứng đột quy não: Biến chứng này xảy ra ở một bệnh nhân với biến chứng rung nhĩ nhanh sau thủ thuật kèm theo tiếp dục chảy máu khoang màng phổi sau thủ thuật. Bệnh nhân sau đó được mở khí quản và chăm sóc lâu dài. Tác giả Joseph Bavaria nghiên cứu trên 36 bệnh nhân được điều trị bằng phương pháp Hibrid đặt stent graft vùng zone 0 cũng ghi nhận 15 bệnh nhân (chiếm $42 \%$ ) có biểu hiện rung nhĩ. Đây là nguyên nhân trực tiếp và hay gặp của biến chứng nhồi máu não. Ngoài ra còn có nguyên nhân trôi mảng xơ vữa động mạch chủ gây nhồi máu não cũng được đặt ra. Cho tới nay cũng chưa có khuyến cáo nào nói về biện phòng ngừa biến chứng nhồi máu não do rung nhĩ ở bệnh nhân can thiệp vùng zone 0 động mạch chủ. Do đó vẫn cần những thông tin của những nghiên cứu với số lượng bệnh nhân lớn hơn và thời gian theo dõi dài hơn.

\subsubsection{Hạn chế.}

Hạn chế trong nghiên cứu của chúng tôi là số lượng bệnh nhân còn ít so với các nghiên cứu khác do đó các thông số thống kê chưa có ý nghĩa thật sự thuyết phục. Chúng tôi hy vọng sẽ tiếp tục thực hiện những nghiên cứu với cỡ mẫu lớn hơn.

\section{KẾT LUẬN}

Với những tiến bộ không ngừng về kỹ thuật và cải tiến dụng cụ trong y học nói chung và trong tim mạch can thiệp nói riêng, việc thực hiện điều trị bằng phương pháp ít xâm lấn ngày càng được ứng dụng ở hầu hết các thể bệnh đòi hỏi can thiệp ngoại khoa. Phương pháp Hybrid đã được áp dụng để điều trị thể bệnh phức tạp nhất của động mạch chủ với những nghiên cứu với số lượng bệnh nhân ngày càng lớn và thời gian theo dõi ngày càng dài, đã trở thành phương pháp điều trị thay thế hiệu quả phẫu thuật kinh điển. Việc áp dụng phương pháp này ở 5 bệnh nhân đầu tiên đã cho thấy tính hiệu quả và khả thi về mặt kỹ thuật cũng như qua thời gian theo dõi trên 12 tháng.

\section{TÀI LIỆ THAM KHẢO}

1. Nguyễn Lân Việt. Thực hành bệnh tim mạch 2015. Trang 405 - 429.

2. Borst HG, Walterbusch G, Schaps D. Extensive aortic replacement using "elephant trunk' prosthesis. Thorac Cardiovasc Surg 1983;31:37-40.

$10.1055 / \mathrm{s}-2007-1020290$ [PubMed] [CrossRef].

3. Kent et al. Results of type II hybrid arch repair with zone 0 stent graft deployment for complex aortic arch pathology. [Jtcvs.org]

4. Criado FJ. A percutaneous technique for preservation of arch branch patency during thoracic endovascular aortic repair (TEVAR): retro- grade catheterization and stenting. J Endovasc Ther 2007; 14:54-8.

5. Vladimir Makaloski et al. Endovascular total arch replacement techniques and early results. Ann Cardiothorac Surg. 2018 May; 7(3): 380-388.

6. Chuter TAM. Branched and fenestrated stent grafts for endovascular repair of thoracic aortic aneurysms. J Vasc Surg 2006; 43:A111-5.

7. Yoshihiko Kurimoto, MD, PhD, Ryushi Maruyama, MD, et al. Thoracic Endovascular Aortic Repair for Challenging Aortic Arch Diseases Using Fenestrated Stent Grafts From Zone 0. [annalsthoracicsugery.org]

8. Joseph Bavaria et al. Hybrid approaches in the treatment of aortic arch aneurysms: Postoperative and midterm outcomes. [Jtcvs.org].

9. Ourania Preventza et al. Zone zero hybrid arch exclusion versus open total arch replacement. Ann Cardiothorac Surg. 2018 May; 7(3): 372-379.

10. Safi HJ, Miller CC, 3rd, Estrera AL, et al. Staged repair of extensive aortic aneurysms: long-term experience with the elephant trunk technique. Ann Surg 2004;240:677-84. [프 free article] [PubMed] 
11. Nadia Vallejo, MD, Julio A. arch repair using propensity score-matching Rodriguez-Lopez, MD, Panniz Heidari, MBS, analysis. Eur J Cardiothorac Surg 2014;46:32-39. Grayson Weatley, MD, David Caparrelli, MD, Venkatesh Ramaiah, MD, and Edward B. Diethrich, MD. Hybrid repair of thoracic aortic lesions for zone 0 and 1 in high-risk patients. [jvascsurg.org]

12. Criado FJ, Barnatan MF, Rizk Y, et al. Technical strategies to expand stent-graft applicability in the aortic arch and proximal descending thoracic aorta. Journal of Endovascular Therapy 2002;9 Suppl 2:II32-II38. $10.1177 / 15266028020090 S 206$

[PubMed]

\section{[CrossRef]}

13. Leontyev S, Misfeld M, Daviewala $\mathrm{P}$, et al. Early- and medium-term results after aortic arch replacement with frozen elephant trunk techniques-a single center study. Ann Cardiothorac Surg 2013;2:606-11. [PMC free article] [PubMed]

14. Thoraflex Hybrid IDE Study. Available online: Clinicaltrials.gov. ID: NCT02724072.

15. Iba Y, Minatoya K, Matsuda H, et al. How should aortic arch aneurysms be treated in the endovascular aortic repair era? A riskadjusted comparison between open and hybrid

\subsection{3/ejcts/ezt615 [PubMed] [CrossRef]}

16. Benedetto U, Melina G, Angeloni E, et al. Current results of open total arch replacement versus hybrid thoracic endovascular aortic repair for aortic arch aneurysm: A meta-analysis of comparative studies. J Thorac Cardiovasc Surg 2013;145:305-06. 10.1016/j.jtcvs.2012.09.011 [PubMed] [CrossRef]

17. Tokuda Y, Oshima H, Narita Y, et al. Hybrid versus open repair of aortic arch aneurysms: comparison of postoperative and midterm outcomes with a propensity score-matching analysis. Eur J Cardiothorac Surg 2016;49:14956. 10.1093/ejcts/ezv063 [PubMed] [CrossRef]

18. Bavaria J, Vallabhajosyula P, Moeller $\mathrm{P}$, et al. Hybrid approaches in the treatment of aortic arch aneurysms: Postoperative and midterm outcomes. J Thorac Cardiovasc Surg 2013;145:S85-90. 10.1016/j.jtcvs.2012.11.044 [PubMed] [CrossRef]

19. Esposito G, Cappabianca G, Bichi Samuele, et al. Hybrid repair of Type A acute aortic dissections with the Lupiae technique: Tenyear results. J Thorac Cardiovasc Surg 2015;149:S99-S104. 10.1016/j.jtcvs.2014.07.099 [PubMed] [CrossRef] 